Covered in: Web of Sciences (WOS); EBSCO; ERIH+; Google Scholar; Index Copernicus; Ideas RePeC; Econpapers; Socionet; CEEOL; Ulrich ProQuest; Cabell, Journalseek; Scipio; Philpapers; SHERPA/RoMEO repositories; KVK; WorldCat; CrossRef; CrossCheck

2018, Volume 10, Issue 1, pages: 45-53 | doi: https://doi.org/10.18662/rrem/16

\section{The Importance of Adopting National Policy Papers on Dual Careers in the Field of Sport}

\section{Liliana BUDEVICI - PUIU ${ }^{1}$}

${ }^{1}$ Associate Professor, PhD., State University of Physical Education and Sport, Chisinau, Republic of Moldova, lbudevici@yahoo.com

\begin{abstract}
The relevance of physical education for sport to society is promoted by many states in order to achieve its social values, especially health, social inclusion, education and volunteering. For example, Liechtenstein regards sport as a cultural component in society, being perceived as being of public interest. The Czech Republic, Estonia and Hungary emphasize through reforms implemented in the field of education and sports, encouraging young people to watch and take part in sporting events and to be informed about sports regularly. The economic aspects of sport, especially the sustainable financing of sporting activities for all and the elaboration of policies based on concrete elements, can be considered as strategic objectives of the Republic of Moldova. In this context, the adoption of normative acts that will lead to the establishment of a framework of national guidelines on double careers will have the effect of regulating those concrete measures regarding the education, work, health and financial means of athletes. At the same time, ensuring the continuation of physical activity levels and national policies in this area, as well as continuously promoting the regular exchange of information and good practice on the role of physical activities to improve the health of the population, are also objectives that can be Implemented at national level in close synergy and cooperation with the World Health Organization (WHO).
\end{abstract}

Keywords: reforms, education, sport, double careers, athletes, good practices.

How to cite: Budevici-Puiu, L. (2018). The Importance of Adopting National Policy Papers on Dual Careers in the Field of Sport. Revista Romaneasca pentru Educatie Multidimensionala, 10(1), 45-53. https://doi.org/10.18662/rrem/16 
Actuality. Sport is an important area for society, because it contributes essentially to local, regional and rural development. Also, sport generates synergies with tourism development by providing infrastructure and forming partnerships in order to finance it and recreational activities.

Athletes' career has a psychological impact upon them on reaching the age that leads them to give up on high-performance sports activities, which create to them certain feelings of anger, frustration, anxiety with reference to the future. In this respect, education can contribute to the development of the elite sportsmen career and their public image. Thus, it is necessary that educational sports process shall be combined with a sufficient academic one, so that the individual can manifest itself in other fields (the development of transferable skills).

According to Roger Bambuk (Bambuck, 2004) (French athlete, former world champion in 1968 in the $100 \mathrm{~m}$ trial and later developing his career as general inspector for national education), asserted in a study that athletes are a category of human resources, possessing in their professional activity unsafe working conditions, employers benefiting from physical condition, resistance and athletic strength in order to use them in the working process, and then eliminate them without giving them another development opportunity.

Moreover, we can say that athletes do not manage to combine sports competitions with higher education, if they do not go through an educational path adapted to the availability of the time planned for these activities and in close agreement with their professional development requests. Therefore, there is also the matter in the case with the insertion of elite athletes in the labour market. On the other hand, studies on performance factors in sport do not always introduce the advocacy for professional career to withdraw from sport, as an important factor in order to increase the success of the elite athletes.

Dorothee Alfermann and Natalia Stambulova, in the paper Career Transitions and Career Termination - Handbook of Sport Psychology, mentioned that there are three theories defining the professional life of an athlete (DC4AC - RO, 2016):

- Sports carrier is a multiannual voluntary sports activity independently selected by a person and has the aim of reaching a high performance in competitions taking place in an year or cycle of sporting events;

- Sports career can be defined as a succession of stages and transitions that includes both initiation stage and participation one in sports competitions, and its endpoint is the result of a personal choice or a dramatic event;

- Sports career is a life-long process, both in the sport and outside. 
According to this theory there are some parameters that characterize the individual's career:

a. duration of participation in competitions;

b. degree of specialization (category);

c. performance objectives (records, medals, etc.);

d. benefits (financial, moral, etc.);

e. costs (investments);

f. personal gratification.

g. professional work (social recognition)

Concerning the results of retirement from sports, studies have shown that, in general, not one but a combination of factors is responsible for ending participation in sports performance activities. The main factor in completing the sports career was identified as both involuntary and voluntary. Among the most frequent factors we can list: lesions, nonselection in representative groups, personal choice and, last but not least, age. We could assert that involuntary and sudden retirement from the sports career is often difficult because athletes are not ready for such a transition.

An important role in underling and deciding on termination of a sports career is the process itself, a strategic approach to the transition phase that starts with its analysis and continues with the evaluation of one's own person in an effort to catalogue the competences register and personal and professional skills available to it at a certain point in time (DC4AC, 2016). This is proving to be the most optimal tool for identifying the goals and resources available to the individual at the time for the purpose of formulating some strategies. Thus, setting goals and drawing up a life plan are probably the most appropriate strategies for completing a sports career, and if developed in a direct connection with the national adopted policies, surely the transition from a successful sports career to another, could characterize the athletes, that they have a high level of self-esteem and a strong competitive identity.

The combination of sports careers with the requirements and constraints of the educational system as well as those associated with the labour market are often difficult to achieve. Thus, in order to avoid situations where athletes have to choose between studies and sports, or work and sports, it is important for them to show a high level of motivation, engagement, resistance, responsibility and a common sense. In this context, the "dual career" should be beneficial to the sport and at the same time enable athletes to study and work, to encourage the development of a new career once with the completion of sports career, to protect and facilitate their situation. 
In this context, although at this stage the athlete's participation in competitions ends, new priorities and professional opportunities such as academia, coaching or business may appear in his life. Among the most common goal-setting strategies, we can mention those reflected in Figure 1.

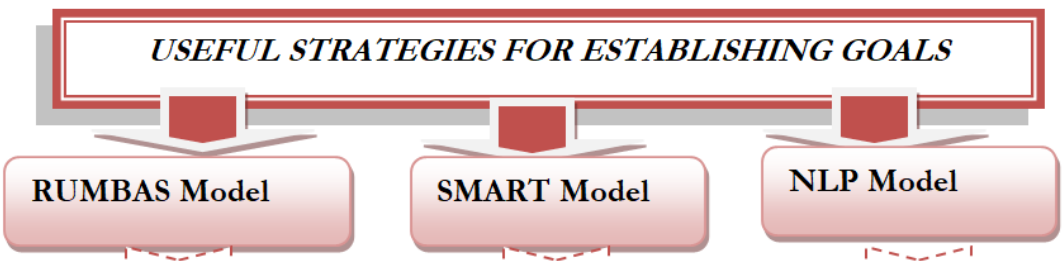

\begin{tabular}{|c|c|c|}
\hline $\begin{array}{l}\text { - Realistic-goal should be } \\
\text { rational but tangible; } \\
\text { - Clear-it can be } \\
\text { expressed, communicated } \\
\text { and understood by others; } \\
\text { - Measurable - change can } \\
\text { be observed and assessed; } \\
\text { - Behavioral - goal should } \\
\text { include concrete action } \\
\text { steps; } \\
\text { - Approved-goal should } \\
\text { be approved and accepted } \\
\text { by those who could be } \\
\text { involved; } \\
\text { - Specific-the goal may be } \\
\text { described by one or more } \\
\text { observable behaviors, it is } \\
\text { not general. }\end{array}$ & $\begin{array}{l}\boldsymbol{S}=\text { Specific: what do you want } \\
\text { to get? Why is it important to do } \\
\text { this now? How do you want to } \\
\text { reach the goal? } \\
\boldsymbol{M}=\boldsymbol{M} \text { easurable: the point is } \\
\text { that what we cannot measure } \\
\text { cannot manage and so we can } \\
\text { not monitor success. } \\
\boldsymbol{R}=\boldsymbol{R} \text { ealistic/ } \boldsymbol{R} \text { elevant: } \\
\text { Realistically, it is not synonym of } \\
\text { easy, but rather high enough to } \\
\text { feel fulfilled and satisfied after } \\
\text { you touch it. } \\
\boldsymbol{T}=\boldsymbol{T i m e} \text { Limit: To highlight } \\
\text { the importance of establishing } \\
\text { deadlines for our actions, it is } \\
\text { enough to quote Andy Szekely: } \\
\text { "Goals are dreams with } \\
\text { deadlines". }\end{array}$ & $\begin{array}{l}\text { - Sets the goal in positive } \\
\text { terms } \\
\text { - Describes the goal in } \\
\text { sensory terms } \\
\text { - Specifies the goal in a } \\
\text { convincing way for you } \\
\text { - Runs a "Quality Control" } \\
\text { verifying that it is } \\
\text { consistent with the } \\
\text { others aspects of your } \\
\text { own life } \\
\text { - Auto-initiation and } \\
\text { maintenance } \\
\text { - The contextual situation } \\
\text { of the goal } \\
\text { - Identifies the resources } \\
\text { you need to reach the } \\
\text { goal } \\
\text { - Evidence Procedure }\end{array}$ \\
\hline
\end{tabular}

Figure 1. Useful strategies of goal setting

The aim of our research is to gather information from specialists in order to identify proposals for the adoption of national policies on dual careers in the field of sport.

The research methodology has been selected to respond to the main requirements specific to a constatational study. The methodological system was composed of: the survey method; the self-observation method; the method of systematic observation and the method of analyzing the products of the activity. In order to obtain the necessary information, we used the questionnaire and the overall synthesis of the answers is not supposed to be exhaustive. It provides a significant overview of the situation found in the analysis of the dual careers regulatory framework for sport. 
The research was conducted within sporting organizations (sports clubs, sports federations on sporting branches, sports schools) as well as among active athletes who withdrew from sports.

The White Book of Sport states that "in order to ensure the reintegration of professional athletes into the labour market at the end of their sports careers, the Commission stresses the importance of taking into account as early as possible the need to provide young athletes and sportsmen with a dual career and to provide high quality training centres to protect their educational, professional and moral interests." The challenge has led to the development of the European Athlete's Double Career Guide, a document that highlights the need to plan strategies that will give athletes new chances of achievement to the completion of their sports career.

Thus, problem of ensuring the double career for athletes, after their withdrawal from the competition activity, must be a priority in adopting policies, not only at European level, but also nationally and internationally.

\section{Interpretation of the results obtained}

On the question "Do you think that more attention needs to be paid to a dual career of athletes at national level? If the answer is yes, can you list certain situation factors, characteristics in this regard? "(Fig. 2). The responses recorded were positive, and among the factors listed by respondents, we can mention: the early closure of the sports career according to the normal life; athletes are required to choose between education and sports at a younger age; young athletes aspiring to a professional career are usually not successful; incompatible sports career earnings with the existence of a decent living, etc.

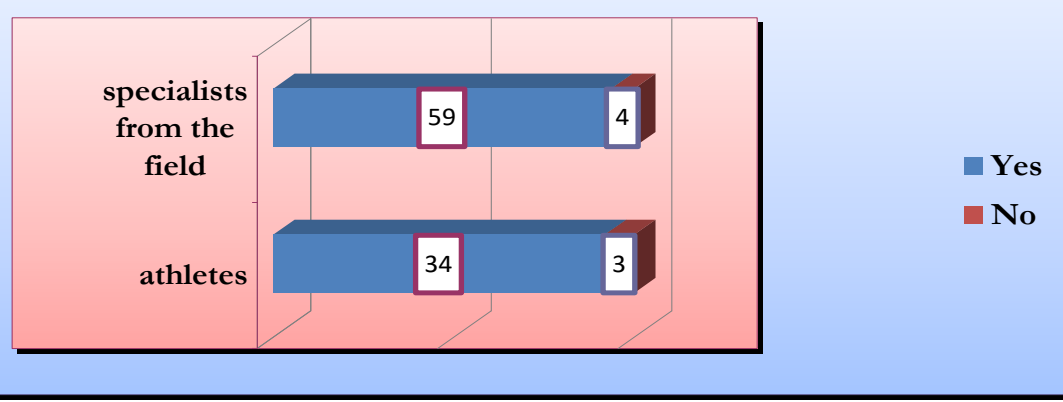

Figure 2. Graphical representation of responses to the attention given to a dual career of athletes at national level

According to the European statistics on the issue we can mention that the data is alarming. Thus, only one out of 50 to 70 elite athletes has 
secured financial security when completing his sports career; $61 \%$ of former Italian footballers, $60 \%$ of former English footballers do not perform any activity after they have withdrawn from their career (FIGC 2009, Sports Illustrated 2009 XPRO 2013). Also, in most developed countries, about half of the elite athletes did not attend professional training until the end of their sports career and only a few European universities have adopted special academic study plans for talented and elite athletes. At the same time, the statistical data reflected that there are needed years of negotiations to establish a suitable partnership for the athletes to be guaranteed after the sports career (for example, it took six years of efforts and discussions at the nongovernmental and governmental level, with three different governments, that the athletes of the Union of Professional Football Professionals in Slovenia to be able to pass a draft law on the provision of funds for the completion of the sports career or for the granting of the special pension for professional athletes).

In the field of sport, a "dual career" involves starting, developing and successfully completing a high-performance sports career in a long-term career, articulating it with the pursuit of the educational and / or employment objective, as well as with other important issues, such as ensuring a social position, a stable and secure income, and the formation of a strong personality in society. Moreover, the athletes' dual career is in close association with the goodwill of those in key positions in institutions or organizations, when an organized approach would be desirable, focusing on financial and legal determinants. Athletes train for participation in international competitions, which complicates the process of studying. Planning an individualized route in education or distance learning requires a lot of effort, while securing additional "holidays" is a problem for the labour market. Studies show that in relation to other employees, athletes are disadvantaged in the labour market. Employers believe that they do not always succeed. Organizations may perceive it as difficult to adapt to changing the needs of athletes they have at different stages of their careers.

In most EU Member States there are a large number of regulations regarding talented sportsmen. These regulate the functioning of training centers as well as the duration of training that is limited by education or labour law for professional athletes.

For example, in France, institutions where the training of athletes takes place must sign an agreement with the educational establishment where they can continue their studies at the same time. The subject matter of the agreement refers mainly to the timetable of the athletes, so that individual exams can be planned during competitions, with the possibility of 
providing them with a guide. The UEFA licensing system for football clubs imposes on them as every young player included in the youth development program has the possibility to go through the educational path obligatorily according to the national legislation without having to give up studies for the benefit of sports activity.

Also, France, Finland and the United Kingdom, through cooperation with domestic government authorities and economic agents, have been able to adapt their local systems both from the educational point of view and at the sporting level, which has allowed the athletes to successfully combine the two processes (training and studies).

The double career of athletes is characterized by generating some benefits for them, provided that they are involved in specialized programs (compared with athletes who face a lack of coordination between sports and studies). According to the scientific research in the field of sport, the following benefits can be noticed:

- related to health (a balanced lifestyle, low stress level, increased wellbeing);

- related to development (better conditions for developing skills in sport, education and other aspects of life, development of personal identity, positive effects of self-regulation skills of athletes);

- social development (socialization development by creating specific networks, expanding connections between peers);

- related to withdrawal from sport and the possibility of easily fitting to the specifics of life after withdrawal from sports activities;

- better employment prospects (access to well-paid jobs and higher employment).

From the realized study through the issue research and taking into account the recommendations made at European level in this direction, we identified some proposals that could be the subject of national policy projects on the regulation of the dual career of elite athletes or young sportsmen /women to participate in international competitions and achieve successful performances (Fig.2).

In the Member States of the European Union, the authorities of the central government forward for approval to the national governments various national policies in the field of sport. Thus, they contribute essentially to the formulation of practical solutions in the field of reference, ie by regulating the dual career of athletes. Concretely, the double career of athletes can be ensured by concluding and finalizing inter-ministerial agreements and distributing funds to sports organizations, sports federations and other third parties (sports clubs, coaches and professional athletes) 
interested in recognizing and supporting the importance double careers of talented athletes.

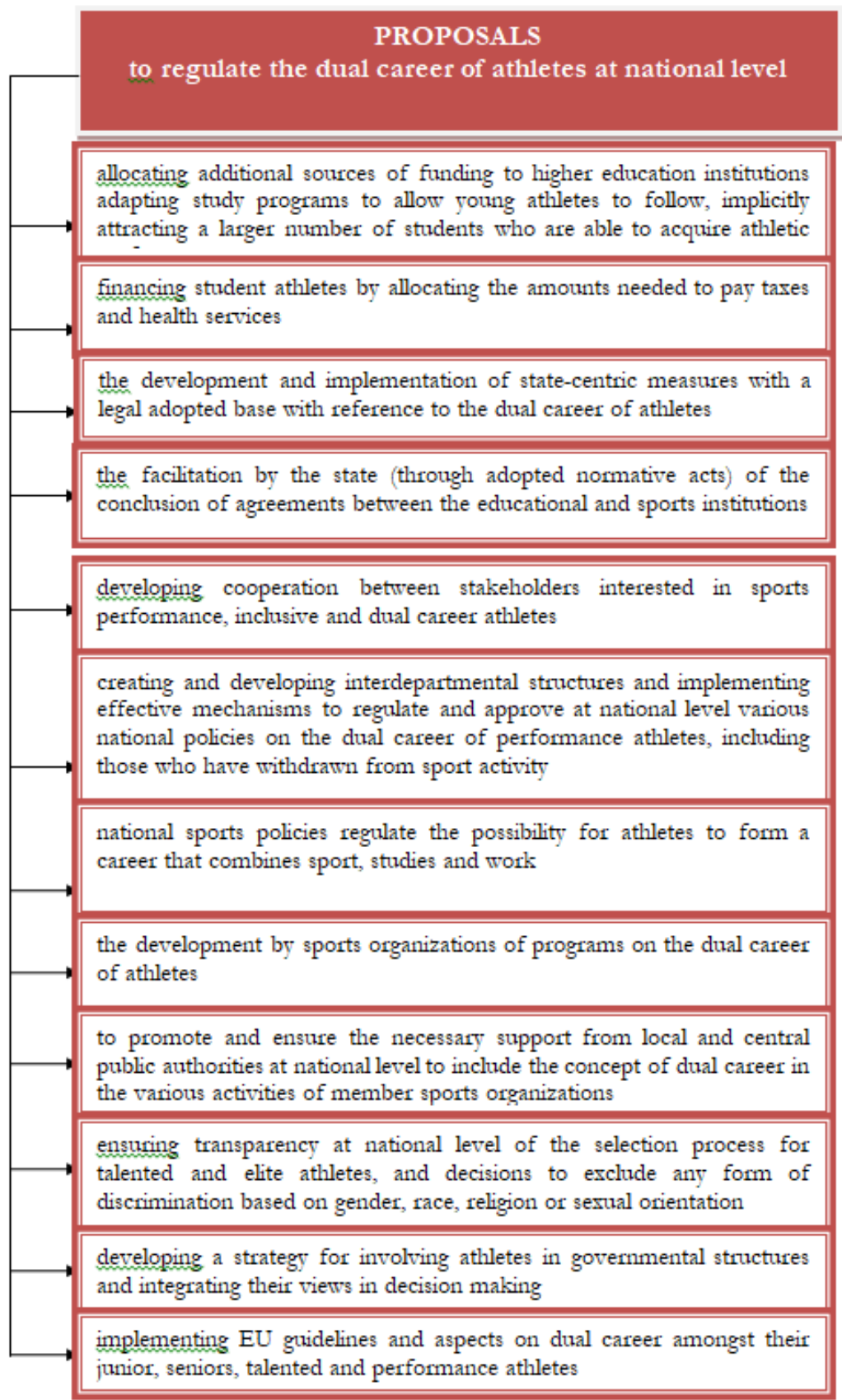

Figure 3. Proposals to regulate the athletes' double careers at national level 
In the Member States of the European Union there are sports academies set up by professional clubs and national federations providing extra-sporting services especially for talented athletes for the purpose of identifying and selecting talented athletes. Local public authorities, educational institutions and sports entities are involved in these academies through the development of agreements in this respect, the main object of which is to obtain benefits and successes in sport. Private academies, including private institutions, provide the training of talented athletes, contribute to the professional training of young athletes and their professional development, which provides them with multilateral education through the support of coaches, teachers and specialists from various fields. In this context, sports academies operate according to a program that strikes a balance between top-level training and athletes' education.

Concluding, we can mention that the adoption of national policies on dual career in sport could contribute to:

- developing the necessary skills of the coaches, their level of qualification considering the role they have in the athletes career;

- improving the technical, tactical, physical and mental capabilities of athletes, as well as developing their personal, social and lifestyle competences through educational means; athletes;

- acquiring transversal / practical skills and personal development of

- developing the sustainability of the national business environment;

- sustainable development of the sport;

- to the elaboration and implementation of legal mechanisms regarding the double career of athletes (stipulation and inclusion of specific provisions thereof in the collective or individual labour agreements concluded by sports with the main coaches and other members of the administration of sport institutions empowered to work effectively with talented and elite athletes.

\section{References}

Bambuck, R. (2004). Le crepuscule des dieux: des symptomes au diagnostic. :

Editions de la Maison des Sciences de l'Homme

DC4AC - RO. (2016). DC4AC - O scurta prezentare. Retrieved from http://www.dc4ac.ro/

DC4AC. (2016). Centrul regional pentru politici si sprijin pentru dubla cariera a sportivilor Retrieved from http://www.dc4ac.ro/ 